\title{
Wasting away: \\ To sludge or not to sludge?
}

\author{
L Nicolle MD FRCPC ${ }^{1}, M$ Miller MD ${ }^{2}$ \\ ${ }^{1}$ Editor-in-Chief, The Canadian Journal of Infectious Diseases, University of Manitoba, \\ Winnipeg, Manitoba; ${ }^{2}$ Department of Microbiology, Division of Infectious Diseases, \\ Sir Mortimer B Davis Jewish General Hospital and McGill University, Montreal, Quebec
}

F llowing a century of high standards of sanitation, food

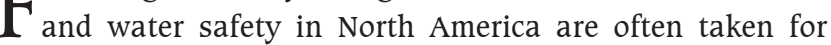
granted. Recent outbreaks of illness attributed to food and water contamination, however, have challenged this complacency. Now, sludge is added to the list of concerns. Sewage sludge is the muddy substance that remains after the treatment of municipal sewage. This material includes not only human waste, but also household and industrial toxic wastes disposed of in local sewers. Federal and provincial Canadian regulations support the use of this material as fertilizer, within acceptable guidelines, as does the Environmental Protection Agency in the United States. The safety of sludge, however, is questioned by some individuals and groups. Specifically, the risk of infectious agents and toxins to work- ers or other exposed individuals, and the potential for heavy metals and organic chemicals to be transferred from sludgetreated fields into crops are concerns.

Is sludge dangerous or beneficial? This question has become another polarizing issue in the public health discourse. Viewpoints tend to divide along the perspectives of the environmentalist or industry, as with many other issues in developed countries. Two individuals with expertise in this topic and representing the two different perspectives have contributed discussions to this issue of The Canadian Journal of Infectious Diseases. These commentaries should outline the controversy for journal readers, as well as provide insight into the specific issues relevant to the opposing arguments. 


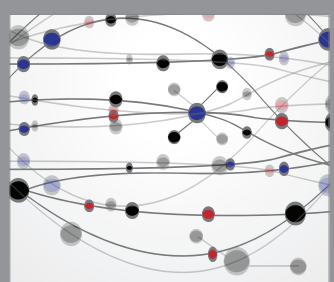

The Scientific World Journal
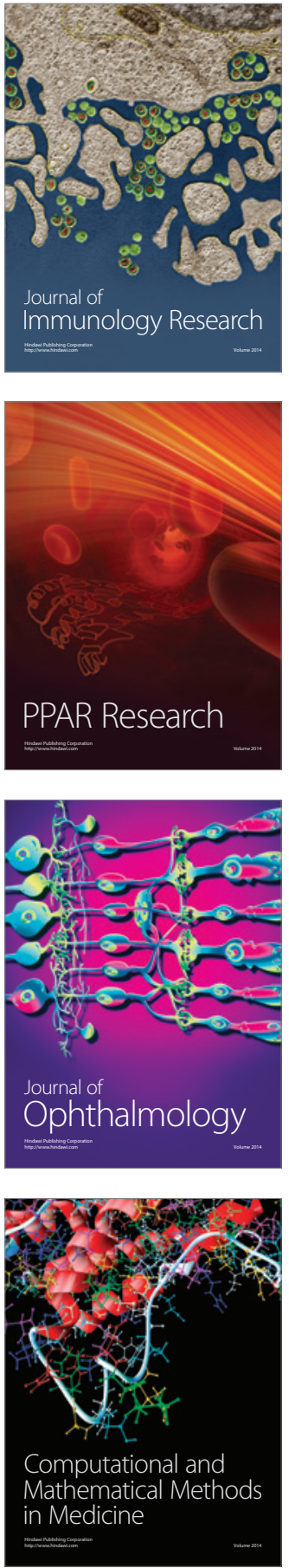

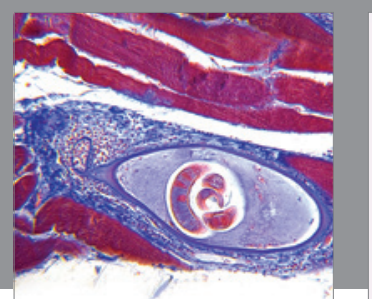

Gastroenterology Research and Practice

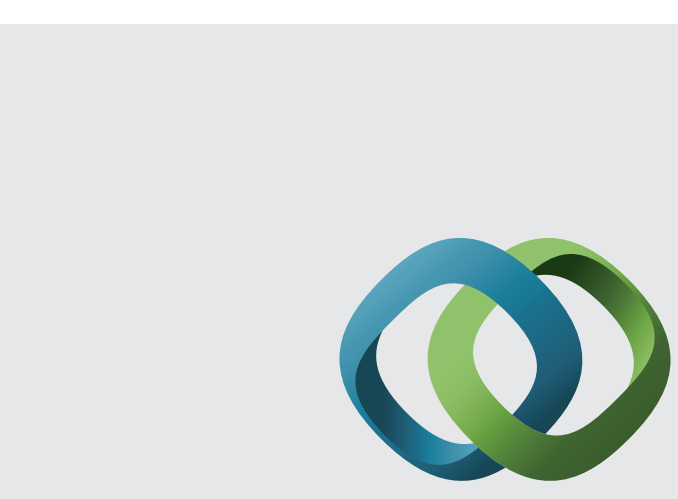

\section{Hindawi}

Submit your manuscripts at

http://www.hindawi.com
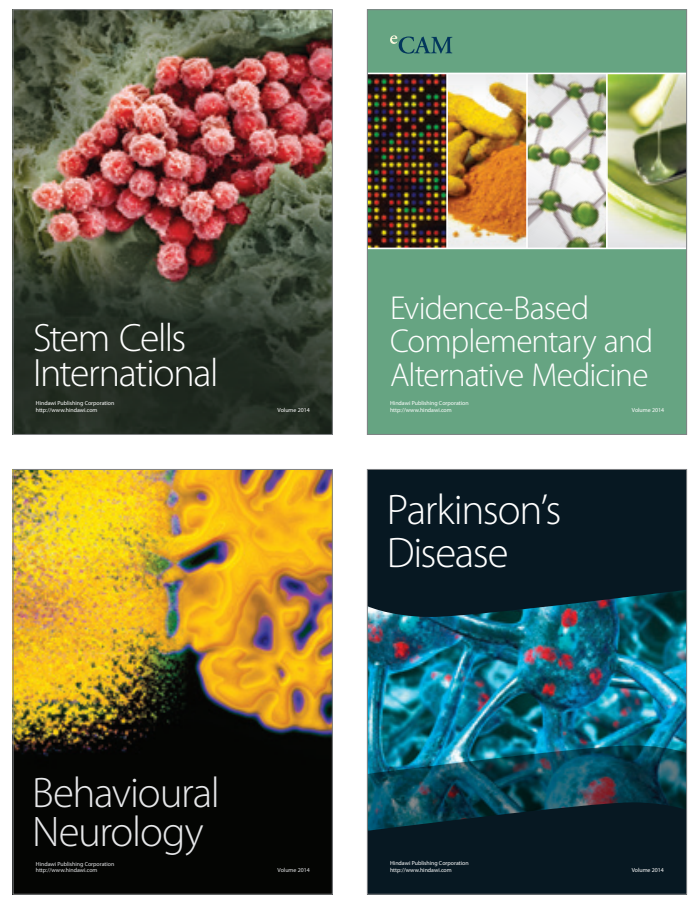
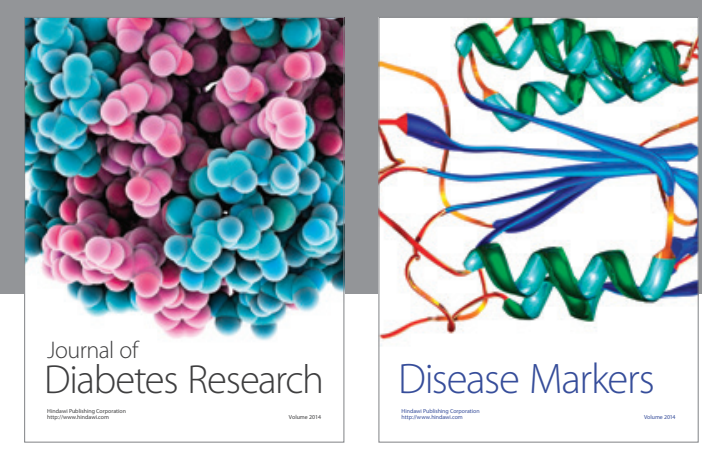

Disease Markers
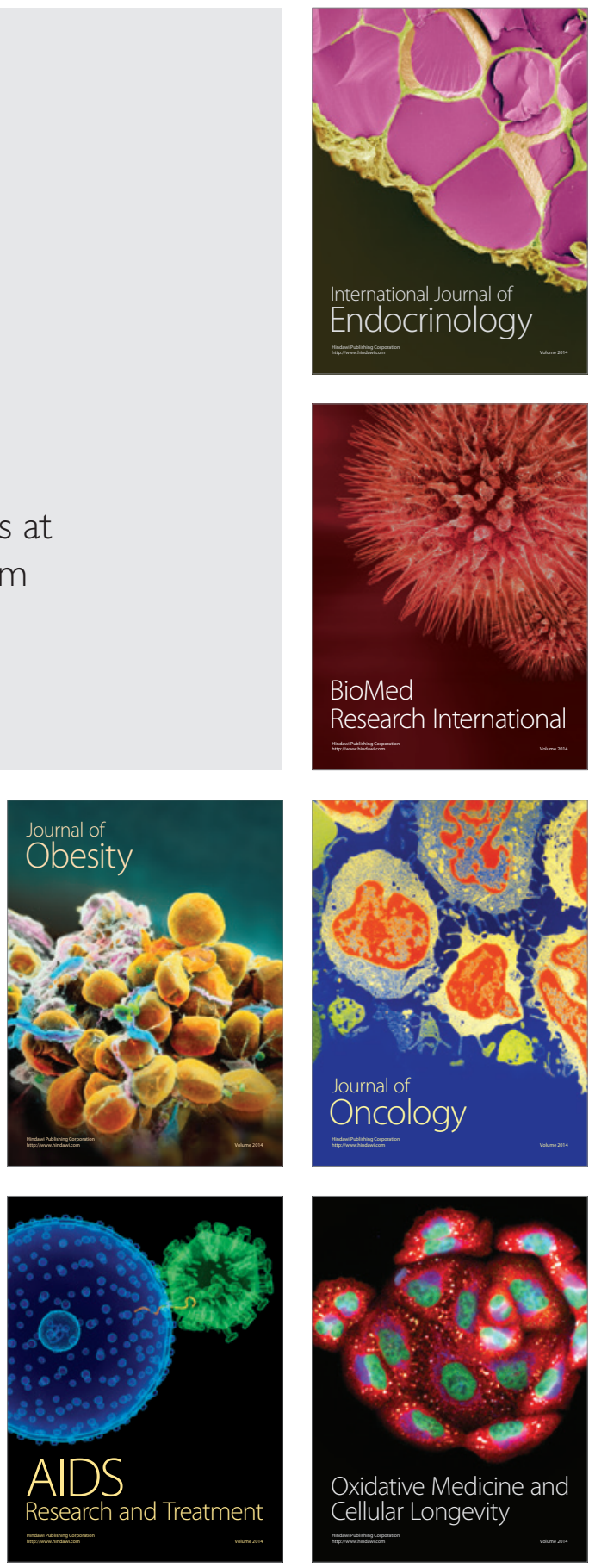